\title{
Validation and field application of tailor-made nitrogen dioxide passive samplers
}

\author{
S. Bootdee $\cdot$ P. Chalemrom $\cdot$ S. Chantara
}

Received: 3 June 2011/Revised: 6 October 2011/Accepted: 21 November 2011/Published online: 20 April 2012

(c) CEERS, IAU 2012

\begin{abstract}
This study describes the validation and field application of new tailor-made passive samplers for nitrogen dioxide measurements. These samplers consist of polypropylene diffusion tubes containing glass fiber filters impregnated with $20 \%$ triethanolamine. The tube was constructed from locally made material. The sampler is simple, lightweight, cheap, easy to use and suitable for simultaneous and multipoint measurements. Nitrogen dioxide concentrations obtained from the passive samplers were strongly correlated with chemiluminescence analyzer $(r=0.924)$. The nitrogen dioxide measurements by the passive samplers have been recorded at 20 sampling sites in Chiang Mai City, Thailand, once a month (3 days of exposure) from November 2007 to April 2008. The sampling sites were located across the city in alignment with the major wind direction. The highest nitrogen dioxide concentrations (28.1-45.1 ppbv) were found in the urban areas with high level of traffic density and human activity. Meteorological conditions, i.e., wind direction/speed and precipitation, were considered for their influence on nitrogen dioxide concentrations. Due to a calm wind occurring during the sampling, its direction had, therefore, no significant effect on nitrogen dioxide concentrations collected from the different locations. However, the mean nitrogen dioxide concentrations were higher at the
\end{abstract}

S. Bootdee $\cdot$ P. Chalemrom

Environmental Science Program, Faculty of Science,

Chiang Mai University, Chiang Mai 50200, Thailand

S. Chantara $(\square)$

Environmental Chemistry Research Laboratory (ECRL),

Department of Chemistry, Faculty of Science,

Chiang Mai University, Chiang Mai 50200, Thailand

e-mail:sp_chan@chiangmai.ac.th downwind sites than at the upwind locations. Unlike wind, rain precipitation obviously affected pollutant concentration levels. In regard to the spatial and temporal variations of nitrogen dioxide concentrations in the study sites, it was deduced that their levels were much more affected by local activities, such as traffic density and biomass burning, rather than meteorological factors.

Keywords Air pollution - Diffusion tube . Local made sampler · Passive sampling

\section{Introduction}

Nitrogen dioxide $\left(\mathrm{NO}_{2}\right)$ is an important indicator of air pollution. It is considered the most toxic form of nitrogen oxide $\left(\mathrm{NO}_{\mathrm{X}}\right)$ generated from motor vehicles, as well as fossil fuel combustion in general and the ever growing urbanized demand for electrical power. When nitrogen dioxide is inhaled it is a strong respiratory irritant. The bronchotracheal and alveolar region are the predominating sites of action. Nitrogen dioxide reduces resistance against respiratory infections, causes lung function changes in asthmatics and enhances bronchial responsiveness to allergens. Therefore, many countries require the monitoring of $\mathrm{NO}_{2}$ levels (Delgado-Saborit and Esteve-Cano 2006). The passive samplers for NO2 have been widely used for air quality monitoring (Salem et al. 2009) and in epidemiological surveys (Glasius et al. 1999), because they are simple, lightweight and cheap devices, which can be operated without requiring any power source (Varshney and Singh 2003). According to Fick's First Law, passive samplers are based on the principle of the free flow of pollutant molecules in the air from the sample medium to a collecting medium. $\mathrm{NO}_{2}$ diffuses to the passive sampler 
where its gets absorbed on the triethanolamine (TEA) impregnated mesh. Molecules of $\mathrm{NO}_{2}$ diffused along the tube are trapped within the adsorbent by the formation of a TEA- $\mathrm{NO}_{2}$ complex. After exposure, $\mathrm{NO}_{2}$ is quantified by chemical extraction of nitrite $\left(\mathrm{NO}_{2}{ }^{-}\right)$, which can be determined by colorimetric analysis (Palmes et al. 1976). Nitrites in solution react with sulphanilamide and form a diazonium compound, which on coupling with $\mathrm{N}$-(1Naphthyl) ethylene diamine dihydrochloride (NEDA) form purple azodye (Varshney and Singh 2003).

$\mathrm{NO}_{2}$ concentrations are calculated from the quantity of nitrites captured in the sampler. Tube-type passive samplers were first developed by Palmes and Gunnison (1973) for the monitoring of $\mathrm{SO}_{2}$, and from there have been continuously developed. Behavior of the TEA absorbents and chemical interferences of $\mathrm{NO}_{2}$ measurements were studied in the UK (Kirby et al. 2000). A new passive sampler for $\mathrm{NO}_{2}$ monitoring was developed by Ozden and Dogeroglu (2007). Passive samplers for atmospheric pollutants such as $\mathrm{SO}_{2}, \mathrm{NO}_{2}, \mathrm{O}_{3}$ and $\mathrm{H}_{2} \mathrm{~S}$ in tropical areas were developed and validated by Campos et al. (2010). The badge-type passive sampler for $\mathrm{SO}_{2}$ and $\mathrm{NO}_{2}$ determination was developed in Italy (De Santis et al. 1997). The Willems badge for $\mathrm{NO}_{2}$ monitoring was developed and validated in Sweden (Hagenbjork-Gustafsson et al. 1999). Both tube type and badge type passive samplers have become popular, because both of them serve satisfactorily with slight modifications. Van Reeuwijk et al. (1998) compared tube type and badge type samplers in regard to their robustness and precision and found tube type samplers to be better than badge type samplers.

The $\mathrm{NO}_{2}$ tube-type passive samplers have been continuously developed. Glasius et al. (1999) used acrylic diffusion tubes from Gradko International $(7.1 \mathrm{~cm}$ length and $1.1 \mathrm{~cm}$ i.d.) to monitor $\mathrm{NO}_{2}$ levels in Denmark and Italy. The diffusion tube steel meshes were dipped in a $33 \%$ TEA in acetone and were exposed for 4 weeks. They found that the measurement of $\mathrm{NO}_{2}$ with chemiluminescence and diffusive sampling method showed good agreement between both of the methods.

TEA is the most commonly used absorbent for $\mathrm{NO}_{2}$. However, its optimum volume and concentrations still need to be optimized for each sampling condition. Kirby et al. (2000) suggested that the amount of the TEA used should be 10 or $20 \%$ in de-ionized water and its volume should be in the range of $25-50 \mu \mathrm{L}$. Under these conditions, the passive samplers obtained from Gradko International (7.1 $\mathrm{cm}$ length and $1.1 \mathrm{~cm}$ i.d.) were exposed for 2 weeks. Varshney and Singh (2003) recommended $50 \mu \mathrm{L}$ of $20 \%$ TEA/de-ionized water as the absorbent on the two stainless steel wire meshes. They used an acrylic tube $(7.1 \mathrm{~cm}$ length and internal diameter $1.1 \mathrm{~cm}$ i.d) in a range of between 1 and 4 weeks for the exposure period. Ozden and Dogeroglu (2007) developed a new passive sampler compared with the commercial one (Gradko International). They found good agreement and a strong correlation between the results of the two $(r>0.95)$. Their passive sampler consists of a glass body $(3.98 \mathrm{~cm}$ length and $1.2 \mathrm{~cm}$ i.d) and contains Whatman GF/A filter paper impregnated with $20 \%$ TEA. The samplers were exposed for 7 days. Apart from using TEA as the $\mathrm{NO}_{2}$ absorbent, there was a study from Campos et al. (2010) that used another impregnated solution. They used a polyethylene passive tube $(21 \mathrm{~mm}$ i.d. and $12 \mathrm{~mm}$ length) containing a Whatman 40 (a cellulose filter) impregnated with $0.5 \mathrm{~mol} /$ L KI: $0.2 \mathrm{~mol} / \mathrm{L} \mathrm{KOH}$ in methanol. The concentrations of the new passive sampler compared with a dynamic gas calibrator (Environment, Model EV-3 M) were tested. The correlation between both methods was highly correlated $(r=0.9556, p<0.0001)$ and the detection limits obtained from the passive sampling were $0.21 \mu \mathrm{g} \mathrm{m}^{-3}$ in 7 days and $0.060 \mu \mathrm{g} \mathrm{m}^{-3}$ in 28 days.

After the sampling, the extraction step was performed. De-ionized water (Campos et al. 2010) was used for extraction of $\mathrm{NO}_{2}$ from the exposed samples. The extract was then completed with Saltzman reagent which colorimetrically determines $\mathrm{NO}_{2}{ }^{-}$. Preparation of the Saltzman reagent may be varied; for instance, the ratio of sulfanilamide to NEDA can be 20:1 (Kirby et al. 2000; Royset 1998) or 10:1 (Ahmad et al. 2011). The colorimetric method is based on the Saltzman reagent with spectrophotometry as the most common method for determining $\mathrm{NO}_{2}$ (Ahmad et al. 2011; Campos et al. 2010; Ozden and Dogeroglu 2007). However, chemiluminescence (Ayers et al. 1998) and ion chromatograph (Glasius et al. 1999; Salem et al. 2009) have also been reported as having potential to determine $\mathrm{NO}_{2}$ in ambient air.

Use of passive samplers to monitor pollutant concentrations, micro-scale or local environment such as (1) street canyon effect (Tang and Wang 2007), (2) sampling places and sampler hanging method, e.g., tree branches, streetlight poles, fences and (3) the nearest sources, e.g., traffic (Pirjola et al. 2004) and open burning may influence the level of measured $\mathrm{NO}_{2}$ concentrations significantly.

The purposes of this study were (a) to develop the tailormade tube type passive sampler for $\mathrm{NO}_{2}$ measurement, (b) to monitor spatial and temporal variations of $\mathrm{NO}_{2}$ concentrations in Chiang Mai City, and (c) to assess the influence of meteorological conditions (wind direction/ speed and precipitation) as well as various human activities on ambient $\mathrm{NO}_{2}$ levels collected by passive samplers in different areas. 


\section{Materials and methods}

Development of nitrogen dioxide passive samplers

\section{Selection of sorbent}

The use of three types of cellulose filters (Whatman No.1, 6 and 40) and a glass fiber filter (GF/A) was investigated to compare their abilities as supporters for impregnated solutions. $50 \mu \mathrm{L}$ of $20 \%$ TEA (Ozden and Dogeroglu 2007; Varshney and Singh 2003) was added to each filter type which was contained in a polypropylene (PP) diffusion tube $(5.3 \mathrm{~cm}$ long and $1.3 \mathrm{~cm}$ i.d.). A sampling set consisted of five sampling tubes and three blanks (unopened tube). A set of diffusion tubes were attached in the protective shelter by fixing the opened ends upright and then exposing them for $24 \mathrm{~h}$ next to the air quality monitoring (AQM) station (Pollution Control Department; PCD) at the Yupparaj Wittayalai School in Chiang Mai City $\left(18^{\circ}\right.$ $\left.47^{\prime} 28.43^{\prime \prime} \mathrm{N}, 98^{\circ} 59^{\prime} 24.26^{\prime \prime} \mathrm{E}\right) . \mathrm{NO}_{2}$ concentrations from this station were measured by automatic active equipment based on chemiluminescence technique. Therefore, they will be used as reference values for comparison with passive sampling in this study. After the sampling, $2 \mathrm{~mL}$ of de-ionized (DI) water was added to the tube and the solution was stirred well for $15 \mathrm{~min}$. One millilitre of the solution was mixed with $2 \mathrm{ml}$ Saltzman reagent (NIOSH 1998) for $10 \mathrm{~min}$. After extraction, the absorbance was measured by spectrophotometer (Jasco UV 530, Japan) at $540 \mathrm{~nm}$.

Sensitivity and precision of the $\mathrm{NO}_{2}$ measurement by spectrophotometer were determined in terms of limit of detection (LOD), limit of quantification (LOQ), repeatability and reproducibility. The lowest concentration $(0.02 \mathrm{mg} / \mathrm{L})$ of nitrite standard solution was run in ten replicates. The limit of detection ( $3 \mu \mathrm{g} / \mathrm{m}$ for 1 day; $1 \mu \mathrm{g} /$ $\mathrm{m}^{3}$ for 3 days) was determined as three times the mean standard deviation (SD) of the lowest concentrations. The limit of quantification $\left(6 \mu \mathrm{g} / \mathrm{m}^{3}\right.$ for 1 day; $2 \mu \mathrm{g} / \mathrm{m}^{3}$ for 3 days) was measured as 10 times the mean standard deviation for the same samples. The repeatability and reproducibility were determined as the percentage of relative standard deviation (\% RSD) for 10 replicates of $0.2 \mathrm{mg} / \mathrm{L}$ of $\mathrm{NO}_{2}$ standard solution. They were found to be $<5 \%$ for repeatability (2.1\%) and reproducibility (4.0\%), which represented a high precision of measurement.

\section{Selection of diffusion tubes}

Two types of diffusion tubes with different lengths and internal diameters (i.d.) were selected and tested. The first one was the $5.4 \mathrm{~cm}$ long and $1.4 \mathrm{~cm}$ i.d. polyethylene (PE) tube. The second and third ones were PP tubes, which included a smaller size $(5.3 \mathrm{~cm}$ long and 1.3 i.d.) and a bigger size $(7.7 \mathrm{~cm}$ long and $1.6 \mathrm{~cm}$ i.d.). These PP tubes were applied from the $5 \mathrm{ml}$ and $10 \mathrm{ml}$ syringes (Nipro, Thailand), respectively. The glass fiber filter (GF/A) used as the sorbent was impregnated with $50 \mu \mathrm{L}$ of $20 \%$ TEA. Their absorbance for $\mathrm{NO}_{2}$ absorption efficiency was compared by 24-h exposure of one set of samplers ( 5 sampling tubes and 3 blanks tubes) at the AQM station.

\section{Extraction duration}

The $\mathrm{NO}_{2}$ concentration was analyzed in the form of $\mathrm{NO}_{2}{ }^{-}$. Extraction time was tested by spiking $20 \mu \mathrm{L}$ of $100 \mathrm{mg} / \mathrm{L}$ of $\mathrm{NO}_{2}{ }^{-}$standard solution onto the sorbent (Whatman GF/ A) in three diffusion tubes. They were left for 15 min prior to the extraction by $2 \mathrm{ml}$ DI water. One $\mathrm{ml}$ of the solution was then mixed with $2 \mathrm{~mL}$ of Saltzman reagent. The extraction durations from $5,10,15,20$ and 25 min were then tested with three replicates of each condition. Percent recoveries were calculated to obtain an efficiency of each condition.

\section{Sampling period}

The appropriate passive sampler, which consists of a PP diffusion tube $(5.3 \mathrm{~cm}$ length and $1.3 \mathrm{~cm}$ i.d.) containing a Whatman GF/A filter paper impregnated with $50 \mu \mathrm{L}$ of $20 \%$ TEA, was selected. Sampling duration outdoors was tested using four sampler sets ( 1 set contains 5 sampling tubes and 3 blanks) at the AQM station. A set of the samplers was collected after 1, 3, 5 and 7 days of exposure. Nitrogen dioxide concentrations obtained from each sampling were compared with the reference values taken from the AQM station from the same sampling duration.

\section{Validation of passive sampler}

An accuracy of the results obtained from the passive sampler and spectrophotometric measurement was evaluated and compared with the reference values from the AQM station. Precision is expressed as the percentage of relative standard deviation (\% RSD) and Root Mean Square Error (RMSE) to ensure quality and capacity of the passive sampler. The passive samplers $(n=5)$ were exposed for $24 \mathrm{~h}$. Data were collected in a total of 23 days.

Field application of the developed passive samplers for nitrogen dioxide measurement in Chiang Mai City

Sampling sites were surveyed and randomly selected within four districts of Chiang Mai Province, Thailand. There were 20 sites (Fig. 1, Table 1) in total and can be divided into urban (8 sites), sub-urban (6 sites) and rural (6 


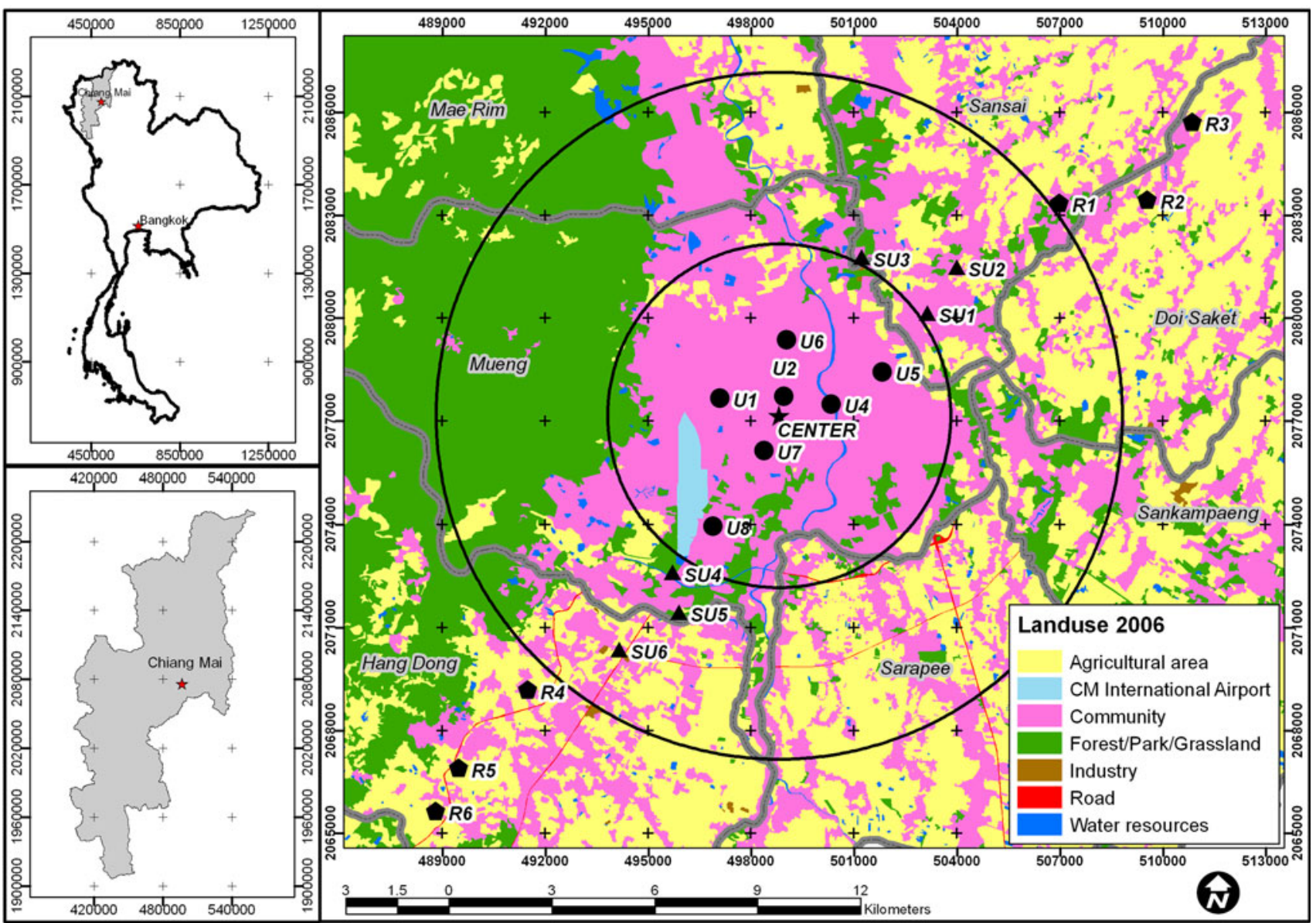

Fig. 1 Sampling sites and land-use pattern of Chiang Mai Province

sites) areas based on population density and human activities. The sampling site categories are defined as follows.

- Urban area: inner circle (5 $\mathrm{km}$ radius from the center). It is the community area including residential and business buildings, Chiang Mai International Airport and the transportation network.

- Sub-urban area: second circle (10 km from the center and $5 \mathrm{~km}$ from the inner circle). Most of this area consists of communities with considerably less density than the urban area.

- Rural area: outer part of the second circle. Most of this area is dedicated to agricultural purposes.

The location of the sampling sites was selected based on the main monsoon direction, which is in the northeastsouthwest direction. The rainy season, influenced by the southwest monsoon, begins in mid-May and continues until October. The cool-dry season begins in November and continues until February. It is influenced by the northwest monsoon, which brings cold air from Siberia, through China and down into Northern Thailand. The hot dry season begins in March and extends to mid-May and is influenced by the southeast monsoon. In this study, sampling was done once a month for 3 days of exposure of the passive samplers in the dry season from November 2007 to April 2008.

Preparation of the passive samplers for nitrogen dioxide measurement

The $\mathrm{NO}_{2}$ passive sampler consists of a PP diffusion tube (5.3 cm length and $1.3 \mathrm{~cm}$ inter diameter) containing a Whatman GF/A filter paper impregnated with $50 \mu \mathrm{L}$ of $20 \%$ TEA. A set of the samplers ( 3 sampling tubes and 1 blank tube) was kept in a shelter to reduce meteorological effects and hung at 1.5-2.0 $\mathrm{m}$ above ground level for 3 days.

\section{Results and discussion}

Selection of nitrogen dioxide passive sampler

Investigation of types of sorbent, diffusion tube and sampling duration for $\mathrm{NO}_{2}$ sampling is summarized in Table 2 . 
Table 1 Sampling site classification and location, potential sources and hanging places of passive samplers for nitrogen dioxide monitoring

\begin{tabular}{|c|c|c|c|c|}
\hline Site & Code & Sampling location & Potential sources & Hanging places \\
\hline \multirow[t]{8}{*}{ Urban } & U1 & Roadside near a parking lot of the Maharaj Hospital & Traffic & Branch of a tree \\
\hline & $\mathrm{U} 2$ & $\begin{array}{l}\text { Backyard of Yupparaj High School, } \sim 2 \mathrm{~m} \text { distance from the } 1.5 \mathrm{~m} \text { height } \\
\text { concrete wall closed to the local road with high traffic density during rush } \\
\text { hour }\end{array}$ & Traffic & $\begin{array}{l}\text { Grillage fence of } \\
\text { the AQM station }\end{array}$ \\
\hline & $\mathrm{U} 3$ & $\begin{array}{l}\text { In front of the shrine located at the business center (big local market), } \sim 1 \mathrm{~m} \\
\text { distance from the motorbike parking place along the small road with dense } \\
\text { buildings (street canyon effect), high traffic density and human activities all } \\
\text { day long }\end{array}$ & $\begin{array}{l}\text { Traffic and incense } \\
\text { burning }\end{array}$ & $\begin{array}{l}\text { Concrete wall of } \\
\text { the shrine }\end{array}$ \\
\hline & U4 & $\begin{array}{l}\text { Police station located near the Ping River and opposite the big local market, } \\
\sim 100 \mathrm{~m} \text { distance from a local road with high traffic density }\end{array}$ & Traffic & Branch of a tree \\
\hline & U5 & $\begin{array}{l}\text { Residential area, parking lot of a } 2 \text { storey-dormitory building closed to the main } \\
\text { bus station, } \sim 500 \mathrm{~m} \text { far from the Super Highway }\end{array}$ & Traffic & Garage pole \\
\hline & U6 & $\begin{array}{l}\text { Small roadside at the backside of Chiang Mai Rajabhat University, residential } \\
\text { area }\end{array}$ & Traffic & Grillage fence \\
\hline & $\mathrm{U} 7$ & $\begin{array}{l}\text { Temple located in a residential area, } \sim 100 \mathrm{~m} \text { distance from a local road with } \\
\text { high traffic density }\end{array}$ & Traffic & Branch of a tree \\
\hline & U8 & $\begin{array}{l}\text { Residential area (house estate) located at the backside of a big department store, } \\
\sim 500 \mathrm{~m} \text { from a highway }\end{array}$ & Traffic & Street-light pole \\
\hline \multirow[t]{6}{*}{$\begin{array}{l}\text { Sub- } \\
\text { urban }\end{array}$} & SU1 & $\begin{array}{l}\text { Near the parking lot of a fresh market, near a } \mathrm{Y} \text { junction, } \sim 100 \mathrm{~m} \text { far from a } \\
\text { highway with high traffic density }\end{array}$ & Traffic & Street-light pole \\
\hline & SU2 & $\begin{array}{l}\text { Small residential area with a low density of housing units, } \sim 150 \mathrm{~m} \text { distance } \\
\text { from a local road }\end{array}$ & Traffic & Grillage fence \\
\hline & SU3 & $\begin{array}{l}\text { Local roadside in front of the small house estate, } \sim 70 \mathrm{~m} \text { from the highway with } \\
\text { high traffic density }\end{array}$ & Traffic & Street-light pole \\
\hline & SU4 & Local roadside, residential area, $\sim 100 \mathrm{~m}$ from a highway & Traffic & Grillage fence \\
\hline & SU5 & Paddy field, $\sim 700 \mathrm{~m}$ distance from a highway & Biomass burning & Branch of a tree \\
\hline & SU6 & $\begin{array}{l}\text { Small residential area, small factories of handcrafted earthenware, surrounded } \\
\text { by paddy fields, } \sim 700 \mathrm{~m} \text { far from the highway }\end{array}$ & $\begin{array}{l}\text { Biomass burning and } \\
\text { smoke from stove }\end{array}$ & Branch of a tree \\
\hline \multirow[t]{6}{*}{ Rural } & $\mathrm{R} 1$ & Small residential area surrounded by orchards and paddy fields & Biomass burning & Grillage fence \\
\hline & $\mathrm{R} 2$ & Small village surrounded by paddy fields & Biomass burning & Street-light pole \\
\hline & $\mathrm{R} 3$ & $\begin{array}{l}\text { Small village surrounded by paddy fields, } \sim 500 \mathrm{~m} \text { from a rice mill and a } \\
\text { highway }\end{array}$ & $\begin{array}{l}\text { Open burning }{ }^{\mathrm{a}} \text { and } \\
\text { rice mill }\end{array}$ & Street-light pole \\
\hline & $\mathrm{R} 4$ & Small residential area & Open burning $^{\mathrm{a}}$ & Branch of a tree \\
\hline & R5 & Small residential area surrounded by paddy fields and orchards & Biomass burning & Branch of a tree \\
\hline & R6 & Small residential area surrounded by orchards and paddy fields & Open burning $^{\mathrm{a}}$ & A house pole \\
\hline
\end{tabular}

Samplers of all sites were hung at $1.5-2.0 \mathrm{~m}$ above ground

${ }^{\text {a }}$ Mainly community garbage

\section{Sorbent selection}

There was no significant difference $(p>0.05)$ between types of sorbent. However, the GF/A provided the highest value of $\mathrm{NO}_{2}(40.5 \mathrm{ppbv})$ and less difference $(6.2 \%)$ from the reference value (43.2 ppbv). Therefore, GF/A was chosen as an absorption filter for $\mathrm{NO}_{2}$ sampling in this study.

\section{Diffusion tubes}

Two types of diffusion tubes including PE $(5.4 \mathrm{~cm}$ long and $1.4 \mathrm{~cm}$ i.d.), and two sizes of PP $(5.3 \mathrm{~cm}$ long and $1.3 \mathrm{~cm}$ i.d. and $7.7 \mathrm{~cm}$ long and $1.6 \mathrm{~cm}$ i.d.) were tested to find out their levels of efficiency in $24 \mathrm{~h}$ exposure. It was found that concentrations of $\mathrm{NO}_{2}$ obtained from the different types of diffusion tube were not significantly different $(p>0.05)$. However, a shorter PP tube $(5.3 \mathrm{~cm})$ was chosen due its low cost and local availability.

\section{Extraction duration for nitrogen dioxide}

The extraction duration is an important step that should be optimized because it can lead to an under or over estimation of pollutants. The times of extraction (5-25 min) were tested. The optimum extraction duration of $\mathrm{NO}_{2}$ from the samplers and reaction times for color developing were at least 15 min. Each step yielded $94 \pm 3 \%$ recovery. 
Table 2 Concentrations of nitrogen dioxide from sorbent types, types of diffusion tube and sampling durations $(n=5)$

\begin{tabular}{llrll}
\hline Development & $\begin{array}{l}\text { Mean } \mathrm{NO}_{2} \\
\text { concentrations } \\
\text { (ppbv) }\end{array}$ & $\begin{array}{l}\% \\
\text { RSD }\end{array}$ & $\begin{array}{l}\text { Reference } \\
\text { value } \\
\text { (ppbv) }\end{array}$ & $\begin{array}{l}\% \\
\text { Difference }\end{array}$ \\
\hline Absorbent types & & & & \\
Whatman No.1 & $38.7 \pm 3.8$ & 9.9 & 43.2 & 10.4 \\
Whatman No.6 & $38.7 \pm 5.1$ & 13.4 & & 10.4 \\
Whatman No.40 $^{2}$ & $37.7 \pm 3.2$ & 8.6 & 12.3 \\
Whatman GF/A & $40.5 \pm 4.4$ & 11.1 & & 6.2 \\
Types of diffusion tube & & & \\
PE & $32.2 \pm 2.1$ & 6.6 & 30.0 & 7.3 \\
PP1 & $31.7 \pm 3.4$ & 10.8 & & 5.7 \\
PP2 & $31.2 \pm 3.3$ & 10.5 & & 4.0 \\
Sampling duration & & & & \\
1 day & $9.0 \pm 1.7$ & 18.9 & 12.0 & 25.0 \\
3 days & $8.5 \pm 1.6$ & 18.8 & 11.7 & 27.4 \\
5 days & $8.3 \pm 0.2$ & 2.4 & 11.2 & 25.9 \\
7 days & $7.0 \pm 2.4$ & 34.3 & 11.2 & 37.5 \\
\hline
\end{tabular}

PP1; Length $(L)=5.3 \mathrm{~cm}$, internal diameter (i.d.) $=1.3 \mathrm{~cm}$

PP2; Length $(L)=7.7 \mathrm{~cm}$, internal diameter (i.d.) $=1.6 \mathrm{~cm}$

${ }^{\text {a }}$ Selected conditions for $\mathrm{NO}_{2}$ passive sampler

Sampling period for nitrogen dioxide

Values of mean $\mathrm{NO}_{2}$ concentration of five replicates subtracted with the average blank value were calculated in ppbv units (Table 2). During 1 week of this test, the ambient $\mathrm{NO}_{2}$ concentrations were relatively low (reference values $=11-12 \mathrm{ppbv}$ ), therefore, the difference of $\mathrm{NO}_{2}$ concentrations obtained from the passive samplers and the reference values were quite high (25-37\%). However, $1-5$ days of exposure provided acceptable values $(<30 \%$ difference) as shown in Table 2. Long sampling times affected the mass diffusion limit depending on the dimension of the sampler such as the size of the cross section (capacity of sorbent), which affected the rate of diffusion in the long exposure time.

Comparison of passive sampler specification and capacity for nitrogen dioxide measurement

Table 3 compares various nitrogen dioxide passive samplers in terms of materials, sizes, absorbent types, extraction reagents and their capacities. Passive samplers made with various kinds of materials such as PP, PE, glass and acrylic were employed in different locations and sampling periods. The sizes of the samplers varied from 10 to $71 \mathrm{~mm}$ length and from 11 to $21 \mathrm{~mm}$ inner diameter. The sampling period ranged from $12 \mathrm{~h}$ to 4 weeks. The popular absorbent used for determination of $\mathrm{NO}_{2}$ in ambient air was 20-50\% TEA absorbed on filter paper or mixed with acetone. Apart from the use of TEA, a solution of potassium iodide and potassium hydroxide (Campos et al. 2010) and sodium hydroxide mixed with sodium iodide (Ayers et al. 1998) was also used as the $\mathrm{NO}_{2}$ absorbent. Common solution used for $\mathrm{NO}_{2}$ extraction was the Saltzman reagent. The extraction durations were slightly different between studies. The precision of the tailor-made passive samplers in this study was compatible to the others (2-15\% precision range). The correlations of $\mathrm{NO}_{2}$ concentrations collected by the passive samplers strongly agreed with active methods in all studies. The tailor-made passive samplers are, therefore, suited to be used for measurement of $\mathrm{NO}_{2}$ in micro-scale environment, where no data are available or the number of active samplers is not sufficient.

\section{Validation of nitrogen dioxide passive sampler}

The $\mathrm{NO}_{2}$ concentrations in the ambient air of the urban area of Chiang Mai Province obtained from passive sampling and spectrophotometry were compared with the reference values from the AQM station (U2 site). It was found that the concentrations of $\mathrm{NO}_{2}$ in the ambient air determined from passive sampling and chemiluminescence were strongly correlated with each other $(r=0.924)$ as shown in Fig. 2. The regression of $\mathrm{NO}_{2}$ concentrations $\left(R^{2}=0.85\right)$ confirms the quantitative agreement between these two methods. The value was much closer to the values reported by Ayers et al. (1998) $\left(R^{2}=0.89\right.$ and 0.81). Moreover, concentrations of $\mathrm{NO}_{2}$ from both techniques were not significantly different $(p>0.05)$. The precision of the passive samplers $(n=5)$ measured from the data over 23 days of the experiment ( $24 \mathrm{~h}$ exposure) was classified as being $65 \%$ high $(<15 \%$ RSD) and $35 \%$ moderate (15-33 \% RSD). The similar experiment was reported by Campos et al. (2010) with $2-15 \% \operatorname{RSD}(n=3)$. It was found that the root mean square errors (RMSE) of $\mathrm{NO}_{2}$ concentrations between the passive sampling and the reference values were 0.94 ppbv. However, the influence of turbulence on passive sampler efficiency is likely to be site dependent (Varshney and Singh 2003).

Spatial and temporal variations of nitrogen dioxide concentrations

Concentrations of $\mathrm{NO}_{2}$ in the urban, sub-urban and rural areas of Chiang Mai Province were obtained from passive sampling and spectrophotometry (Table 4). Ranges of $\mathrm{NO}_{2}$ concentrations over 6 months were 6.3-45.1, 5.1-19.1 and 1.6-8.7 ppbv in urban, sub-urban and rural areas, respectively. One-Way ANOVA was used to determine the differences of mean $\mathrm{NO}_{2}$ concentrations between each area. The $\mathrm{NO}_{2}$ concentrations were log-transformed to achieve normal distribution. The results showed that $\mathrm{NO}_{2}$ 
Table 3 Comparison of nitrogen dioxide passive samplers; materials, sizes, absorbent types, extraction reagents and their capacities

\begin{tabular}{|c|c|c|c|c|c|c|c|c|c|c|}
\hline \multirow{2}{*}{$\begin{array}{l}\text { Study } \\
\text { no. }\end{array}$} & \multicolumn{4}{|c|}{ Passive samplers } & \multirow{2}{*}{$\begin{array}{l}\text { Sampling } \\
\text { period }\end{array}$} & \multirow[t]{2}{*}{ Absorbent } & \multirow{2}{*}{$\begin{array}{l}\text { Extraction } \\
\text { reagent/ } \\
\text { method }\end{array}$} & \multirow{2}{*}{$\begin{array}{l}\text { Correlation } \\
\text { with active } \\
\text { measurement } \\
\text { (or commercial } \\
\text { passive } \\
\text { sampler) }\end{array}$} & \multirow{2}{*}{$\begin{array}{l}\text { Precision } \\
(\%)\end{array}$} & \multirow[t]{2}{*}{ References } \\
\hline & $\begin{array}{l}\text { Commercial } \\
\text { name/tailor } \\
\text { made }\end{array}$ & $\begin{array}{l}\text { Tube } \\
\text { material }\end{array}$ & $\begin{array}{l}\text { Length } \\
(\mathrm{mm})\end{array}$ & $\begin{array}{l}\text { i.d. } \\
(\mathrm{mm})\end{array}$ & & & & & & \\
\hline 1 & Tailor made & PP & 53 & 13 & 3 days & $\begin{array}{l}20 \% \text { TEA, } \\
\text { GF/A }\end{array}$ & $\begin{array}{l}\text { DIW and } \\
\text { Saltzman } \\
(1: 2), \\
15 \text { min } \\
\text { shaken }\end{array}$ & $\begin{aligned} R^{2} & =0.85 \\
r & =0.92\end{aligned}$ & 10.8 & This study \\
\hline 2 & NA & Acrylic & 71 & 11 & 10 days & $\begin{array}{l}50 \% \text { TEA/ } \\
\text { actone }\end{array}$ & $\begin{array}{l}\text { Saltzman, left } \\
10 \text { min, } \\
\text { shaken, left } \\
20 \text { min }\end{array}$ & NA & 6.0 & $\begin{array}{l}\text { Ahmad et al. } \\
\text { (2011) }\end{array}$ \\
\hline 3 & NA & $\mathrm{PE}$ & 12 & 21 & $\begin{array}{l}1 \text { and } \\
4 \text { weeks }\end{array}$ & $\begin{array}{l}\mathrm{KI}+\mathrm{KOH} \text { in } \\
\text { methanol, } \\
\text { Whatman } 40\end{array}$ & $\begin{array}{l}\text { Modified } \\
\text { Griess- } \\
\text { Saltzman } \\
\text { method } \\
(1.5 \mathrm{ml} \\
\text { DIW) }\end{array}$ & $r=0.95$ & $2.0-15.0$ & $\begin{array}{l}\text { Campos } \\
\text { et al. } \\
(2010)\end{array}$ \\
\hline 4 & Tailor made & Glass & 39.8 & 12 & 1 week & $\begin{array}{l}20 \% \text { TEA, } \\
\text { GF/A }\end{array}$ & $\begin{array}{l}5 \mathrm{ml} \\
\text { Saltzman, } \\
40 \text { min } \\
\text { extraction }\end{array}$ & $\begin{array}{l}R^{2}=0.95 \\
\quad(\text { Gradko } \\
\quad \text { International) }\end{array}$ & 8.8 & $\begin{array}{l}\text { Ozden and } \\
\text { Dogeroglu } \\
(2007)\end{array}$ \\
\hline 5 & $\begin{array}{l}\text { Gradko } \\
\text { International }\end{array}$ & Acrylic & 71 & 11 & $12 \mathrm{~h}$. & $\begin{array}{l}33 \% \text { TEA in } \\
\text { acetone }\end{array}$ & $\begin{array}{l}\text { Griess- } \\
\text { Saltzman }\end{array}$ & NA & 6.0 & $\begin{array}{l}\text { Glasius et al. } \\
\text { (1999) }\end{array}$ \\
\hline 6 & $\begin{array}{l}\text { Ferm-type } \\
\text { sampler } \\
\text { (developed } \\
\text { from Palm } \\
\text { tube) }\end{array}$ & $\mathrm{PP}$ ring & 10 & 21 & 1 week & $\begin{array}{l}\mathrm{NaOH}+\mathrm{NaI} \\
\text { in methanol, } \\
\text { Whatman } \\
\text { paper filter }\end{array}$ & $\begin{array}{l}\text { Diazotizing } \\
\text { reagent }\end{array}$ & $R^{2}=0.81-0.89$ & $5.0-10.0$ & $\begin{array}{l}\text { Ayers et al. } \\
\text { (1998) }\end{array}$ \\
\hline
\end{tabular}

$D I W$ Deionized water, $N A$ data was not available

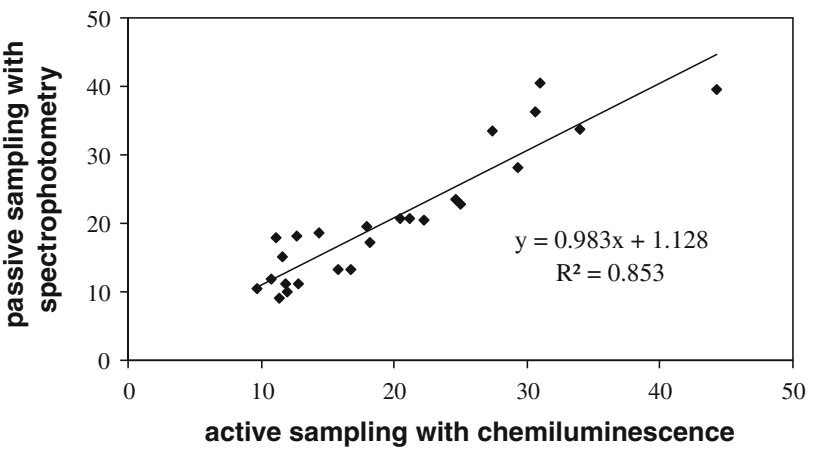

Fig. 2 Correlation of $\mathrm{NO}_{2}$ concentrations (ppbv) determined by passive sampling with spectrophotometry and active sampling with chemiluminescence

concentrations recorded during the sampling period of the rural area were significantly less than those of the urban and sub-urban areas $(p<0.05)$. The concentration levels were also significantly different in both the urban and suburban areas $(p<0.05)$. However, the influences of either the micro-scale or the local environment on the measured $\mathrm{NO}_{2}$ levels were obviously observed. The highest $\mathrm{NO}_{2}$ concentration of each month was found at the U3 site (Waroros Market), which is located in the urban area of Chiang Mai City and experiences high traffic density. The sampling was done in front of the shrine located $\sim 1 \mathrm{~m}$ distance from the motorbike parking area along the small road that had many buildings and high traffic density, along with the significant levels of human activity that occurred throughout the day. The samplers were hung on the concrete wall of the shrine. Therefore, they were exposed to air pollutants from the nearby sources. At this site, traffic volume and the high incidence of incense burning could be seen as the potential sources of $\mathrm{NO}_{2}$, and together with a street canyon effect, all of these factors could likely lead to higher $\mathrm{NO}_{2}$ concentrations (Tang and Wang 2007). Furthermore, similar research studies, which have been reported by Ahmad et al. (2011), presenting the highest concentrations of $\mathrm{NO}_{2}$ were measured near the main road due to the intensive flow of road vehicles. The influence of the micro-scale environment was obviously observed in the cases where the $\mathrm{NO}_{2}$ concentrations were obtained from the $\mathrm{U} 3$ and $\mathrm{U} 4$ (recorded at the police station located near the river, $\sim 100 \mathrm{~m}$ distance from a local road with high 
Table $4 \mathrm{NO}_{2}$ concentrations (ppbv) and precipitation during November 2007-April 2008

\begin{tabular}{|c|c|c|c|c|c|c|c|}
\hline Study area & $\begin{array}{l}\text { Nov- } \\
07\end{array}$ & $\begin{array}{l}\text { Dec- } \\
07\end{array}$ & $\begin{array}{l}\text { Jan- } \\
08\end{array}$ & $\begin{array}{l}\text { Feb- } \\
08\end{array}$ & $\begin{array}{l}\text { Mar- } \\
08\end{array}$ & $\begin{array}{l}\text { Apr- } \\
08\end{array}$ & $\begin{array}{l}\text { Nov- } \\
07-A p r- \\
08\end{array}$ \\
\hline \multicolumn{8}{|l|}{ Urban $(n=8)$} \\
\hline Max & 28.1 & 42.5 & 45.1 & 36.5 & 39.4 & 37.4 & 45.1 \\
\hline Min & 8.4 & 6.4 & 11.3 & 9.4 & 6.3 & 10.1 & 6.3 \\
\hline Mean & 13.5 & 18.9 & 18.9 & 16.6 & 16.1 & 16.6 & 16.7 \\
\hline SD & 7.3 & 10.9 & 11.7 & 8.7 & 10.1 & 8.7 & 9.5 \\
\hline \multicolumn{8}{|c|}{ Sub-urban $(n=6)$} \\
\hline $\operatorname{Max}$ & 10.3 & 15.4 & 17.9 & 18.4 & 19.1 & 17.1 & 19.1 \\
\hline Min & 5.4 & 8.9 & 7.3 & 6.7 & 5.1 & 5.5 & 5.1 \\
\hline Mean & 7.1 & 12.0 & 13.9 & 10.6 & 11.7 & 10.1 & 10.9 \\
\hline SD & 2.6 & 2.8 & 4.3 & 5.0 & 5.5 & 5.1 & 4.2 \\
\hline \multicolumn{8}{|l|}{ Rural $(n=6)$} \\
\hline Max & 4.2 & 8.7 & 6.9 & 6.9 & 7.2 & 5.7 & 8.7 \\
\hline Min & 1.6 & 3.4 & 3.1 & 2.9 & 2.2 & 2.7 & 1.6 \\
\hline Mean & 2.8 & 6.0 & 4.4 & 5.1 & 4.7 & 4.1 & 4.5 \\
\hline SD & 1.0 & 2.2 & 1.5 & 1.7 & 2.2 & 1.4 & 1.7 \\
\hline $\begin{array}{l}\text { Total } \\
\text { precipitation } \\
(\mathrm{mm})^{\mathrm{a}}\end{array}$ & 73.5 & 0 & 16.6 & 13.8 & 9.4 & 57.2 & 170.5 \\
\hline $\begin{array}{l}\text { Precipitation } \\
(\text { day })^{\mathrm{a}}\end{array}$ & 9 & 0 & 2 & 4 & 5 & 8 & 28 \\
\hline
\end{tabular}

a Thai Meteorological Department, 2008

traffic density). The samplers of U4 were hung on tree branches. The location near the river had significantly better air-flow and the pollutant concentrations were diluted at that site. $\mathrm{NO}_{2}$ levels of the $\mathrm{U} 4$ site were, therefore, much lower than those of the U3, even though the two locations were in relatively close proximity to each other. Moreover, the study from Pirjola et al. (2004) revealed that at a distance of 120-140 $\mathrm{m}$ from the source, the pollutant concentrations would be diluted to one-tenth of the values that were recorded within a $9 \mathrm{~m}$ range of the source.

$\mathrm{NO}_{2}$ levels detected in sub-urban and rural areas with less traffic density and particularly higher open burning activities were lower than urban area. This is probably due to range and frequency of source emission as well as the micro-environment of the sampling sites such as density of buildings and human activities. In the area with low density of constructions, air circulation is definitely better and pollutant concentration will be diluted.

Some previous studies (Ezcurra et al. 2001; Ortiz de Zarate et al. 2005; Sahai et al. 2007) have reported that $\mathrm{NO}_{\mathrm{X}}, \mathrm{NO}, \mathrm{NO}_{2}$ and $\mathrm{N}_{2} \mathrm{O}$ were found in the ambient air around biomass burning area and most of the $\mathrm{NO}_{2}$ in the rural area was released from the open burning of agricultural waste. In this study, the $\mathrm{NO}_{2}$ concentrations detected in the rural area were 1.6-8.7 ppbv. When comparing those values with other places, it was found that the $\mathrm{NO}_{2}$
Fig. 3 Mean $\mathrm{NO}_{2}$ concentrations in Chiang Mai during 3 days sampling: a November 2007, b December 2007, c January 2008, d February 2008, e March 2008 and f April 2008. $F S=$ Failed sampling (e.g., broken or lost of sampling tube)

concentrations of Chiang Mai's rural areas were lower than those found in India collected by active sampling (0.9-20.3 ppbv) during the agricultural burning season (Sahai et al. 2007), but were higher than the values found in Spain (2 ppbv) during the cereal burning season (Ezcurra et al. 2001).

In terms of temporal variation, $\mathrm{NO}_{2}$ concentrations of all sites from December 2007 to April 2008 were not found to be significantly different $(p>0.05)$. The concentrations from December 2007 to March 2008 were significantly higher than those in November 2007, while the levels in November 2007 were not significantly different from those in April 2008. The levels of precipitation measured in November 2007 and April 2008 were 73.5 and $57.2 \mathrm{~mm}$, respectively (Northern Meteorological Center, 2008), and were higher than those of other months during the sampling period (Table 3). From this information, the sampling could be divided into two periods: the cool-dry period (December 2007-March 2008) and the transition period (November 2007 and April 2008). The highest $\mathrm{NO}_{2}$ concentration in the urban area was found in January 2008, while that in the rural areas was found in December 2007. It can be concluded that there are more pollutants $\left(\mathrm{NO}_{2}\right)$ present in the dry season. The concentrations are significantly higher than those of the transition period. In the rainy season, the pollutant concentrations were lower than those of both the dry and transition periods. The results agreed with many previous studies (Ramire Sanchez et al. 2009; Ramire Sanchez et al. 2009, 2008).

\section{Geographic distribution of nitrogen dioxide in Chiang Mai}

Figure 3 illustrates plots of $\mathrm{NO}_{2}$ concentrations of all sampling sites in each sampling month (November 2007 to April 2008). Levels of $\mathrm{NO}_{2}$ concentrations were found to correspond with land use type, population density and human activities in the sampling areas. In the urban area, high $\mathrm{NO}_{2}$ concentrations were found in the range from 10 to above $30 \mathrm{ppbv}$. The maximum concentration levels were recorded at the U3 site (45.1 ppbv) in January 2008. However, $\mathrm{NO}_{2}$ concentrations of the $\mathrm{U} 4$ site were approximately 2 times lower than those found in the U3. Even though these two sites were located close to each other, the $\mathrm{NO}_{2}$ levels detected in each site were distinct. It is clear that the major source of pollutants in the urban area was traffic. However, other human activities also influence the $\mathrm{NO}_{2}$ concentration levels. At the U3 site, incense 


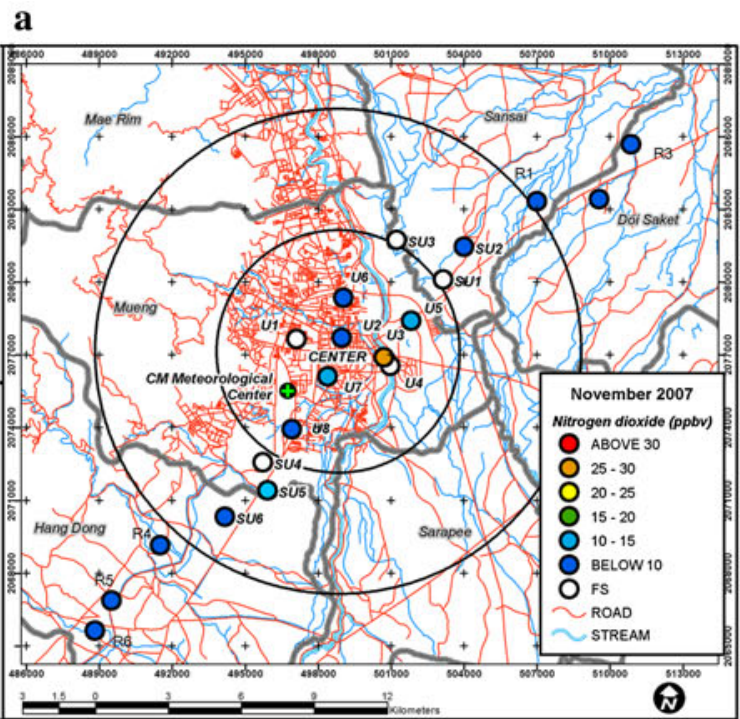

b

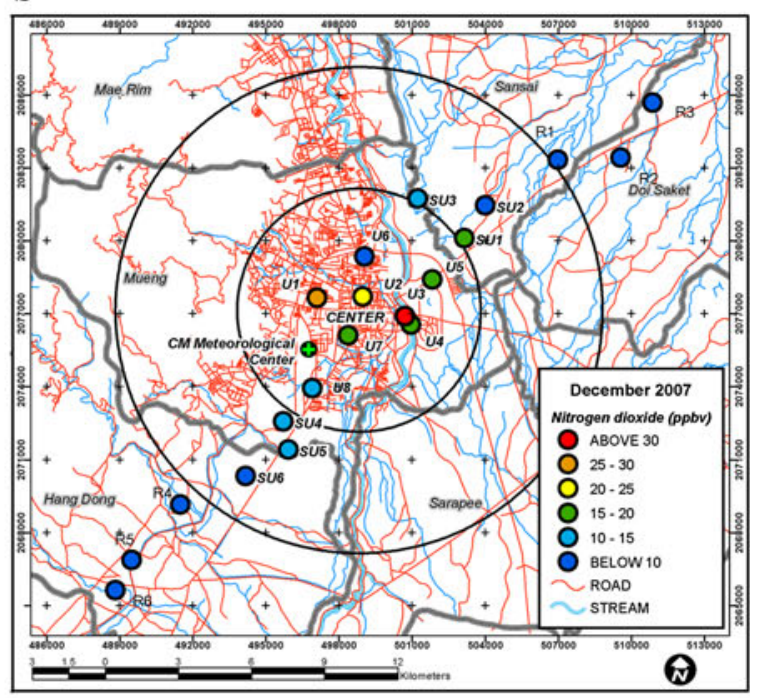

c

d
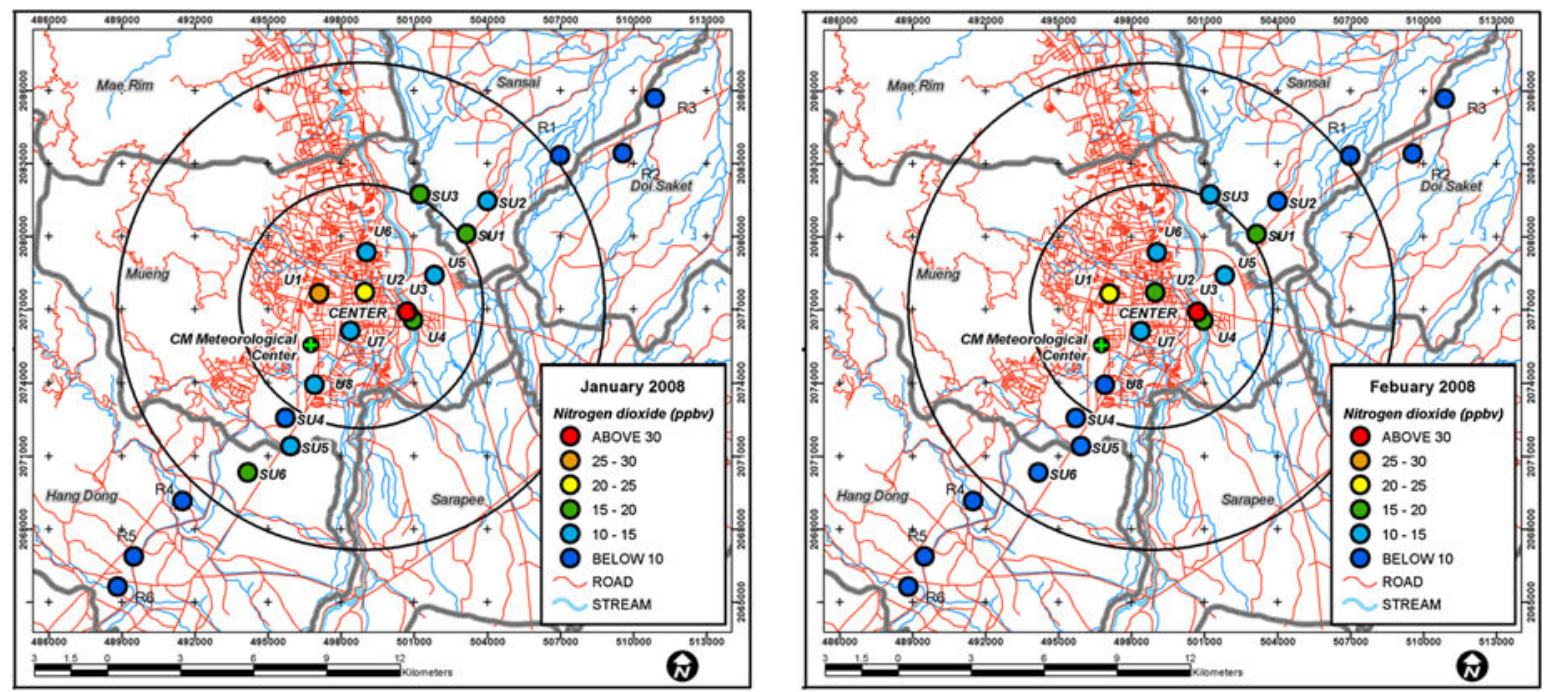

e

f
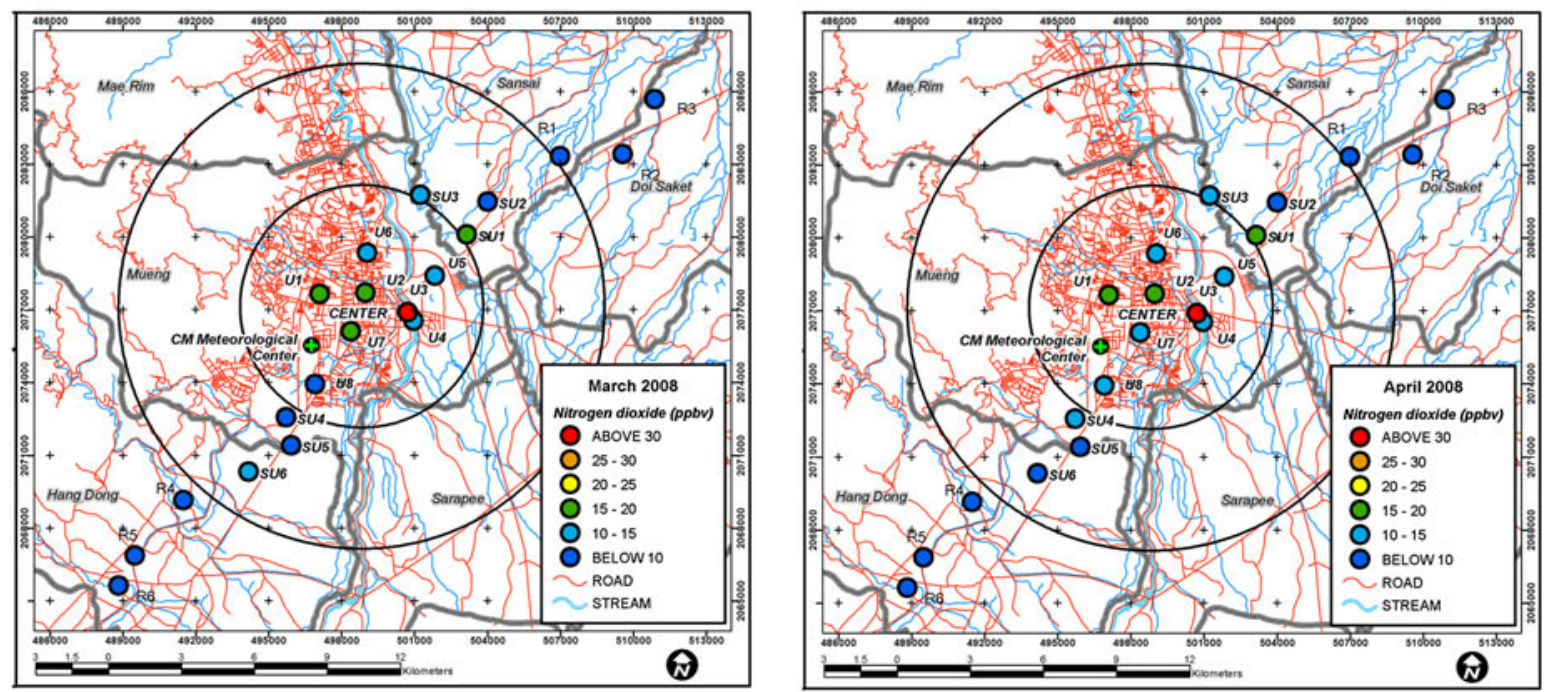


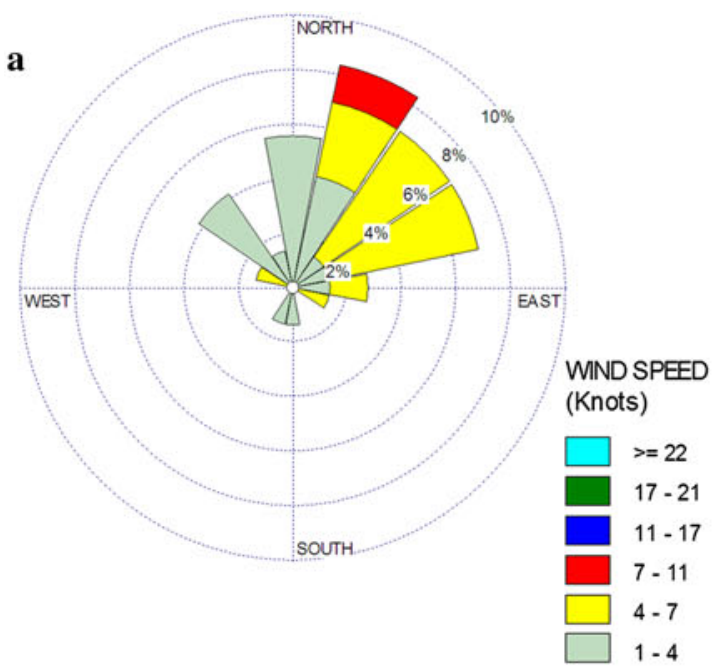

Calms: $58.33 \%$

c

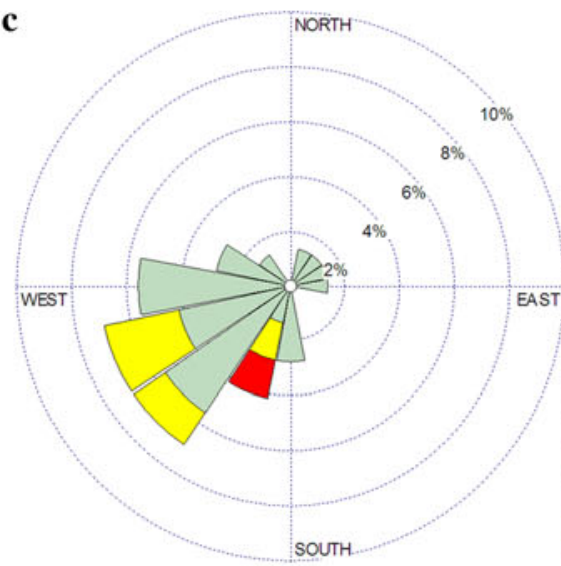

WIND SPEED (Knots)

$\square>=22$

$17-21$

11-17

$7-11$

$4-7$

1. 1.4

Calms: $63.89 \%$

e

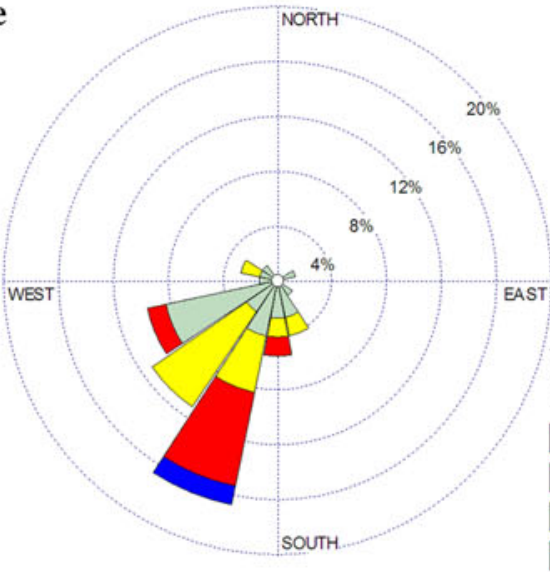

WIND SPEED (Knots)

$\square>=22$

प $17-21$

- $11-17$

7-11

4-7

$1-4$

Calms: $44.44 \%$

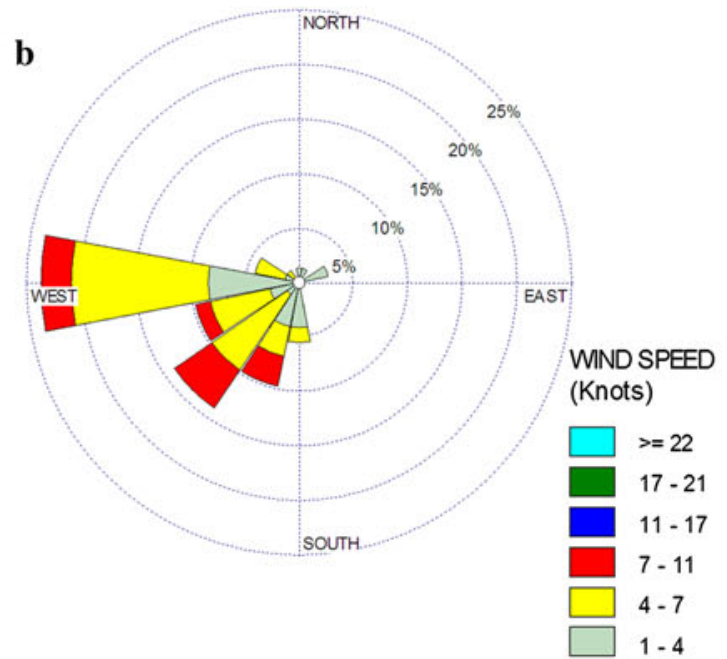

Calms: $26.39 \%$

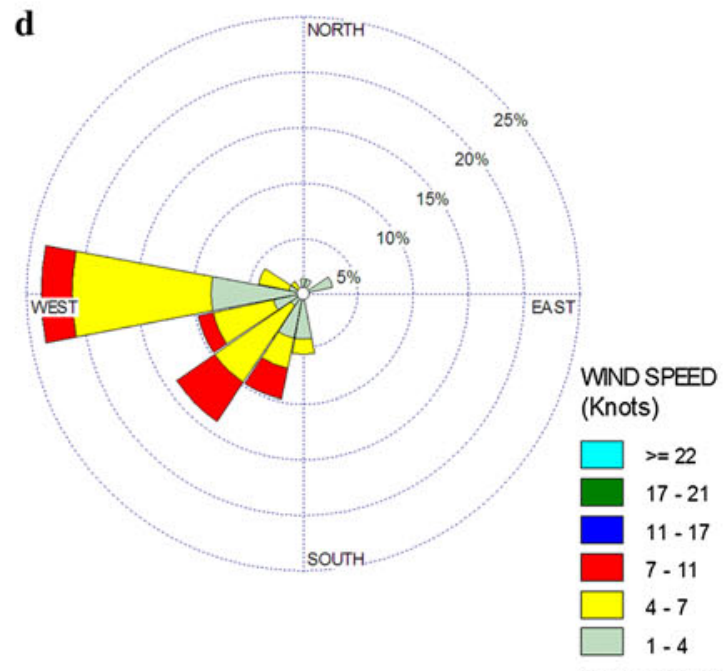

Calms: $26.39 \%$

f

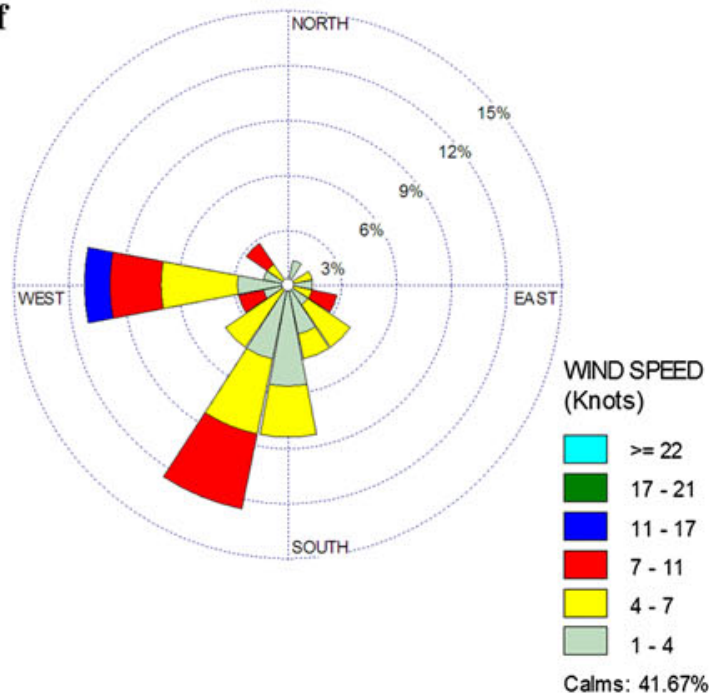


4 Fig. 4 Wind roses of Chiang Mai Province during the 3 days of sampling: a November 2007, b December 2007, c January 2008, d February 2008, e March 2008 and f April 2008. Source: Thai Meteorological Department (Mr. Wiwatt Haoteang)

burning in the shrine nearby the sampling site might very well be the effective $\mathrm{NO}_{2}$ source in this area. Incense burning definitely generates ambient quantities of $\mathrm{NO}_{2}(\mathrm{Lin}$ et al. 2008). $\mathrm{NO}_{2}$ concentrations in sub-urban and rural areas were lower than those in urban area $(<10-20 \mathrm{ppbv})$.

Effect of wind direction/speed on ambient $\mathrm{NO}_{2}$ concentrations

The $\mathrm{NO}_{2}$ concentrations emitted from the urban area can be transported to the sampling sites downwind, which resulted from wind speed/direction (Chiwa 2010). Figure 4 illustrates the wind levels of Chiang Mai Province during the 3 days of sampling in each month. The major wind direction from SW-NE was dominant during the study period except in November, when NE-SW wind prevailed. The range of wind speed in November (58\% calm) and January (64\% calm) was 1-7 knots, while it was about 4-11 knots in December and February; it was classified as $26 \%$ calm and 1-17 knots in March and April while classified as being $44 \%$ calm. Overall wind speed was very weak. The calm condition was about $2 / 3$ of the whole period. Table 5 shows the mean $\mathrm{NO}_{2}$ concentrations of the sub-urban and rural areas located in the NE and SW directions of the city. The data were divided into two groups (sub-urban and rural areas). In each group the sampling sites were separated based on their locations (NE and SW of the city). Wind direction during the sampling was considered in the estimate of its influence on $\mathrm{NO}_{2}$ concentrations downwind. It was found that $\mathrm{NO}_{2}$ concentrations of the sampling sites in the same category of the upwind and downwind directions were not significantly different $(p<0.05)$. However, the concentrations at the downwind sites were higher than those of the upwind sites for all sampling (Table 5). According to the data, the effect of wind is limited in terms of air pollutant transportation. In this case, ambient $\mathrm{NO}_{2}$ concentrations were mainly produced from local activities, i.e., traffic density or biomass burning.

\section{Conclusion}

The tailor-made $\mathrm{NO}_{2}$ passive sampler was successfully validated. The $\mathrm{NO}_{2}$ concentrations obtained from the samplers in comparison with the reference values were strongly correlated. The application of the passive sampler in the field depends on the meteorological and geographic conditions, which might affect the mass diffusion of pollutants. Anthropogenic activities are expected to be the main source of $\mathrm{NO}_{2}$ in ambient air. Therefore, $\mathrm{NO}_{2}$ concentrations in each area were related to size, type and range of activities such as vehicle exhaust, biomass burning, etc. Higher $\mathrm{NO}_{2}$ concentrations were found in the urban areas than in the sub-urban and rural areas during every season.
Table $5 T$ test for equality of $\mathrm{NO}_{2}$ concentrations (ppbv) collected from sub-urban and rural areas located in NE and SW directions of Chiang Mai city

\begin{tabular}{|c|c|c|c|c|c|}
\hline \multirow[t]{2}{*}{ Area } & \multirow[t]{2}{*}{ Month } & \multirow[t]{2}{*}{ Wind direction (Fig. 4) } & \multicolumn{2}{|c|}{ Mean $\mathrm{NO}_{2} \pm \mathrm{SD}$ (ppbv) } & \multirow[t]{2}{*}{$P$ value } \\
\hline & & & NE location & SW location & \\
\hline \multirow[t]{8}{*}{ Sub-urban } & & & $S U 1-S U 3$ & SU4-SU6 & \\
\hline & Nov-07 & NE-SW & NA & NA & - \\
\hline & Dec-07 & $\mathrm{W}-\mathrm{E}$ and SW-NE & $12.58 \pm 3.1^{\mathrm{b}}$ & $11.37 \pm 2.6$ & 0.629 \\
\hline & Jan-08 & $\mathrm{W}-\mathrm{E}$ and SW-NE & $15.32 \pm 1.6^{\mathrm{b}}$ & $12.42 \pm 5.3$ & 0.416 \\
\hline & Feb-08 & SW-NE & $12.94 \pm 5.9^{\mathrm{b}}$ & $8.27 \pm 0.8$ & 0.243 \\
\hline & Mar-08 & SW-NE & $12.52 \pm 7.0^{\mathrm{b}}$ & $10.80 \pm 2.4$ & 0.710 \\
\hline & Apr-08 & SW-NE & $12.22 \pm 6.0^{\mathrm{b}}$ & $7.96 \pm 2.4$ & 0.317 \\
\hline & 6 months & & $12.64 \pm 4.7^{\mathrm{b}}$ & $9.89 \pm 3.2$ & 0.059 \\
\hline \multirow[t]{8}{*}{ Rural } & & & $R 1-R 3$ & $R 4-R 6$ & \\
\hline & Nov-07 & NE-SW & $2.49 \pm 0.7$ & $3.14 \pm 1.0^{\mathrm{b}}$ & 0.406 \\
\hline & Dec-07 & $\mathrm{W}-\mathrm{E}$ and SW-NE & $6.47 \pm 1.3^{\mathrm{b}}$ & $5.53 \pm 2.8$ & 0.624 \\
\hline & Jan-08 & $\mathrm{W}-\mathrm{E}$ and SW-NE & $5.16 \pm 1.6^{\mathrm{b}}$ & $3.60 \pm 0.4$ & 0.177 \\
\hline & Feb-08 & SW-NE & $5.06 \pm 1.9^{\mathrm{b}}$ & $5.13 \pm 1.5$ & 0.961 \\
\hline & Mar-08 & SW-NE & $5.24 \pm 1.7^{\mathrm{b}}$ & $4.12 \pm 2.7$ & 0.573 \\
\hline & Apr-08 & SW-NE & $4.48 \pm 1.4^{\mathrm{b}}$ & $3.63 \pm 1.3$ & 0.496 \\
\hline & 6 months & & $4.82 \pm 1.8^{\mathrm{b}}$ & $4.58 \pm 2.2$ & 0.728 \\
\hline
\end{tabular}


Wind speed and direction might have affected the pollutant concentrations, when the pollutant sources were found to be downwind. In this study it was found that the downwind sampling sites had higher $\mathrm{NO}_{2}$ concentrations than the upwind sites, even though there were no other significant differences.

Acknowledgments The authors also wish to extend their sincere gratitude to all who assisted in promoting the present work.

\section{References}

Ahmad SS, Biiker P, Emberson L, Shabbir R (2011) Monitoring nitrogen dioxide levels in urban areas in Rawalpindi, Pakistan. Water Air Soil pollut. doi:10.1007/s11270-011-0741-9

Ayers GP, Keywood MD, Gillett R, Manins PC, Malfroy H, Bardsleys T (1998) Validation of passive diffusion samplers for $\mathrm{SO}_{2}$ and $\mathrm{NO}_{2}$. Atmos Environ 32(20):3587-3592

Campos VP, Cruz LPS, Godoi RHM, Godoi AFL, Tavares TM (2010) Development and validation of passive samplers for atmospheric monitoring of $\mathrm{SO}_{2}, \mathrm{NO}_{2}, \mathrm{O}_{3}$ and $\mathrm{H}_{2} \mathrm{~S}$ in tropical areas. Microchem J 96:132-138

Chiwa M (2010) Characteristics of atmospheric nitrogen and sulfur containing compound in an inland suburban-forested site in northern Kyushu, western Japan. Atmos Res 96:531-543

De Santis F, Allegrini I, Fazio MC, Pasella D, Piredda R (1997) Development of a passive sampling technique for the determination of nitrogen dioxide and sulfur dioxide in ambient air. Anal Chim Acta 346:127-134

Delgado-Saborit JM, Esteve-Cano V (2006) Field study of diffusion collection rate coefficients of a $\mathrm{NO}_{2}$ passive sampler in a Mediterranean coastal area. Environ Monit Assess 120:327-345

Ezcurra A, Ortiz de Zarate I, Van Dhin P, Lacaux JP (2001) Cereal waste burning pollution observed in the town of Vitoria (northern Spain). Atmos Environ 35:1377-1386

Glasius M, Carlsen MF, Hansen TS, Lohse C (1999) Measurements of nitrogen dioxide on Funen using diffusion tubes. Atmos Environ 33:1177-1185

Hagenbjork-Gustafsson A, Lindahl R, Levin JO, Karlsson D (1999) Validation of a diffusive sampler for $\mathrm{NO}_{2}$. JEM 1:349-352

Kirby C, Fox M, Waterhouse J (2000) Reliability of nitrogen dioxide passive diffusion tubes for ambient measurement. JEM 2:307-312

Lin T-C, Krishnaswamy G, Chi DS (2008) Incense smoke: clinical, structural and molecular effects on airway disease. CMA 6(3). doi:10.1186/1476-7961-6-3
Ortiz de Zarate I, Ezcurra A, Lacaux JP, Van Dinh P, Diaz de Argandona J (2005) Pollution by cereal waste burning in Spain. Atmos Res 73:161-170

Ozden O, Dogeroglu T (2007) Field evaluation of a tailor-made new passive sampler for the determination of $\mathrm{NO}_{2}$ levels in ambient air. Environ Monit Assess. doi:10.1007/s10661-007-9921-x

Palmes ED, Gunnison AF (1973) Personal monitoring device for gaseous contaminants. Am Ind Hyg Assoc J 34:71-78

Palmes ED, Gunnison AF, Dimatto J, Tomezyk C (1976) Personal sampler for nitrogen dioxide. Am Ind Hyg Assoc J 37:570-577

Pirjola L, Parviainen H, Hussein T, Valli A, Hammeri K, Aaalto P, Virtanen A, Keskinen J, Pakkanen TA, Makela T, Hillamo RE (2004) "Sniffer" - a novel tool for chasing vehicles and measuring traffic pollutants. Atmos Environ 38:3625-3635

Ramire Sanchez HU, Andrade Garcia MD, Bejaran R, Garcia Guadalupe ME, Vazquez AW, Pompa Toledano AC, Torre Villasenor O (2009) The spatial-temporal distribution of the atmospheric polluting agents during the period 2000-2005 in the Urban Area of Guadalajara, Jalisco, Mexico. J Hazard Mater 165:1128-1141

Royset O (1998) Comparison of passive and active sampling methods for the determination of nitrogen dioxide in urban air. Fresenius $\mathbf{J}$ Anal Chem 360:69-73

Sahai S, Sharma C, Singh DP, Dixit CK, Singh N, Sharma P (2007) A study for development of emission factors for trace gases and carbonaceous particulate species from in situ burning of wheat straw in agricultural fields in India. Atmos Environ 41:9173-9186

Salem AA, Soliman AA, El-Haty AI (2009) Determination of nitrogen dioxide, sulfur dioxide, ozone and ammonia in ambient air using the passive sampling method associated with ion chromatographic and potentiometric analyses. Air Qual Atmos Health 2:133-145

Tang UW, Wang ZS (2007) Influences of urban forms on trafficinduced noise and air pollution: results from a modeling system. Environ Modell Softw 22:1750-1764

The National Institute for Occupational Safety and Health (NIOSH) (1998) Nitrogen dioxide: Method 6700. NIOSH manual of analytical methods (NMAM), Fourth Edition, pp 4-5

Van Reeuwijk H, Fischer PH, Harssema H, Briggs DJ, Small-bone K, Lebret E (1998) Field comparison of two $\mathrm{NO}_{2}$ samplers to assess spatial variation. Environ Monit Assess 50:37-51

Varshney CK, Singh AP (2003) Passive sampler for $\mathrm{NO}_{\mathrm{X}}$ monitoring: a critical review. Environment 23:127-136

Verm K, Deb MK, Verma D (2008) Determination of nitrogen dioxide in ambient air employing diffuse reflectance Fourier transform infrared spectroscopy. Atmos Res 90:33-40 